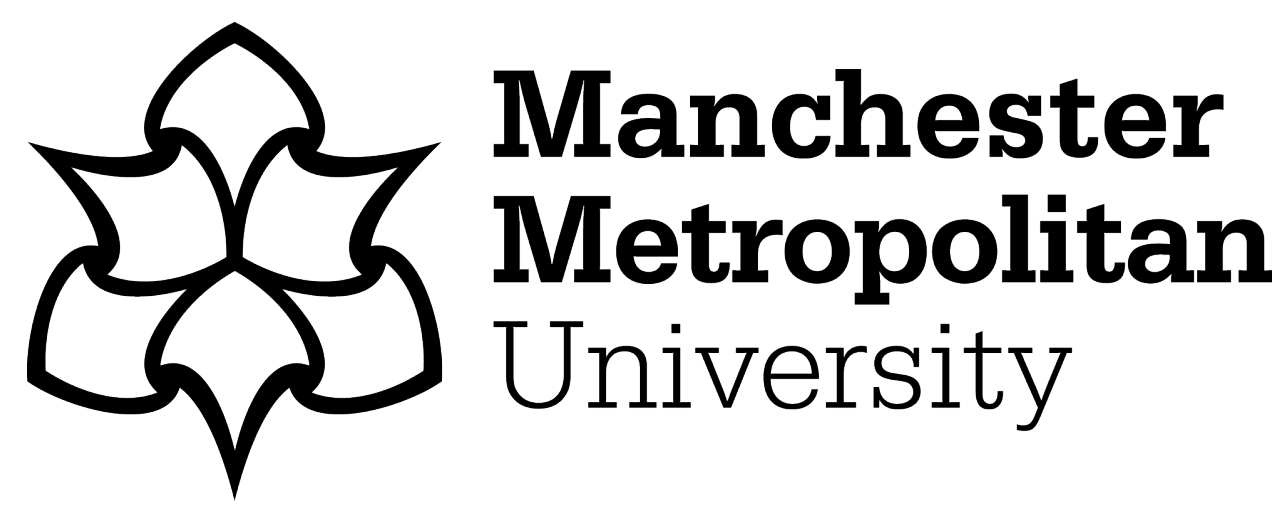

Durand, E, Lobo, P, Crayford, A, Sevcenco, Y and Christie, S ORCID logoORCID: https://orcid.org/0000-0003-2631-5425 (2021) Impact of fuel hydrogen content on non-volatile particulate matter emitted from an aircraft auxiliary power unit measured with standardised reference systems. Fuel, 287. p. 119637. ISSN 0016-2361

Downloaded from: https://e-space.mmu.ac.uk/627088/

Version: Accepted Version

Publisher: Elsevier

DOI: https://doi.org/10.1016/j.fuel.2020.119637

Usage rights: Creative Commons: Attribution-Noncommercial-No Derivative Works 4.0

Please cite the published version 
Full Length Article

\title{
Impact of fuel hydrogen content on non-volatile particulate matter emitted from an aircraft auxiliary power unit measured with standardised reference systems
}

\author{
Eliot Durand $^{\mathrm{a}, *}$, Prem Lobo ${ }^{\mathrm{b}, *}$, Andrew Crayford $^{\mathrm{a}}$, Yura Sevcenco ${ }^{\mathrm{a}}$, Simon Christie ${ }^{\mathrm{c}}$ \\ ${ }^{\text {a }}$ Gas Turbine Research Centre, Cardiff University, Cardiff, United Kingdom \\ ${ }^{\mathrm{b}}$ Metrology Research Centre, National Research Council Canada, Ottawa, Ontario, Canada \\ ${ }^{\mathrm{c}}$ Centre for Aviation, Transport and the Environment, Manchester Metropolitan University, Manchester, United Kingdom
}

A R T I C L E I N F O

Keywords:

Aircraft emissions

Non-volatile particulate matter

Sustainable aviation fuel

Auxiliary power unit

Fuel hydrogen content

Particle loss correction

\begin{abstract}
A B S T R A C T
Replacement of conventional petroleum jet fuel with sustainable aviation fuels (SAFs) can significantly reduce non-volatile Particulate Matter (nvPM) emissions from aircraft main engines and auxiliary power units (APUs). As part of the Initiative Towards sustAinable Kerosene for Aviation (ITAKA) project, the impact of fuel hydrogen content on nvPM number and mass emissions and particle size distributions were investigated using a GTCP85 APU burning blends of conventional (Jet A-1) and Hydrotreated Esters and Fatty Acids (HEFA)-derived (Used Cooking Oil and Camelina) aviation fuels. The measurements were conducted during two separate test campaigns performed three years apart, each employing a different regulatory compliant sampling and measurement reference system for aircraft engine nvPM emissions. The objective was to investigate the correlation of fuel hydrogen content with nvPM number and mass emissions at the engine exit plane (EEP) independent of fuel composition, measurement system, and ambient conditions. The nvPM number and mass emissions and size distributions systematically decreased with increasing fuel hydrogen content regardless of the fuel composition or APU operating condition. The measured nvPM emissions were particle loss-corrected to the EEP and normalised to a common fuel hydrogen content. Similar rates of nvPM reductions were observed for both test campaigns at all investigated APU operating conditions, confirming that engine exit nvPM reductions correlate with fuel hydrogen content for fuels of relatively similar compositions. This analysis method can be applied to emissions data from other engine types to compare the reduction in nvPM emissions for sustainable aviation fuels and blends.
\end{abstract}

\section{Introduction}

Aviation is an essential mode of transportation in the modern world, connecting nations, economies, and facilitating the transportation of goods. The air transportation industry has been estimated to provide about twelve million skilled jobs and contributes over 700 billion euros to Europe's economy [1], with a global average annual growth rate of $2 \%$ forecasted between 2017 and 2040 for aircraft movements [2]. The aviation sector is a fast-growing source of greenhouse gas emissions, currently representing $1.7-2.3 \%$ of global carbon emissions [3]. In a globalised world facing the consequences of climate change, deterioration of local air quality, and increased scarcity of resources, the continuous growth of aviation has led to extensive research and development towards more fuel-efficient engine technologies, and sustainable aviation fuel (SAF) sources to reduce the environmental impact. To address $\mathrm{CO}_{2}$ emissions from international aviation and consistent with the aviation industry's commitment to carbon neutral growth from 2020, the International Civil Aviation Organization (ICAO) implemented the Carbon Offsetting and Reduction Scheme for International Aviation (CORSIA), a global market-based measure [4].

Aircraft gas turbine engines emit ultrafine Particulate Matter (PM) typically $<100 \mathrm{~nm}$ in mean diameter [5-8]. Within the boundary layer, these emissions are associated with reduced air quality and have the potential for adverse health impacts in the vicinity of airports [9-11]. Aircraft gas turbine engines are also the main anthropogenic source of $\mathrm{PM}$ emissions in the upper atmosphere at cruising altitudes [12], with

\footnotetext{
* Corresponding authors.

E-mail addresses: durandef@cardiff.ac.uk (E. Durand), Prem.Lobo@nrc-cnrc.gc.ca (P. Lobo).
} 
soot contributing to contrail cirrus formation and radiative forcing [12-14].

In order to mitigate the impact of aircraft engine PM emissions, ICAO has recently adopted new regulatory methodology for the sampling and measurement of aircraft engine nvPM mass and number emissions, with a new nvPM mass regulatory standard effective 1 January 2020 for inproduction turbofan and turbojet engines with rated thrust greater than $26.7 \mathrm{kN}$ [15]. Aircraft engine nvPM is defined as particles exiting an aircraft engine that do not volatilise when heated to a temperature of $350{ }^{\circ} \mathrm{C}$ and consist essentially of soot or black carbon [15]. When measuring aircraft engine nvPM emissions, the extracted exhaust aerosol must be diluted and cooled, in order to supress condensation and nucleation of volatile species present in the gas phase, before being transported and analysed by diagnostic instruments [16]. A standardised sampling and measurement system has been developed by the Society of Automotive Engineers (SAE) Aircraft Engine Gas and Particulate Emissions Measurement (E-31) committee [16] and adopted by ICAO as described in "Annex 16 - Environmental Protection Volume 2 Aircraft Engine Emissions" to the Convention on International Civil Aviation [15]. The development of this standardised methodology, described in SAE Aerospace Recommended Practice (ARP) 6320 [16], was achieved using results of multiple aircraft engine emission tests and experimental work conducted primarily during the Studying, sAmpling and Measuring of aircraft ParticuLate Emissions (SAMPLE) campaigns [17-23] and Aviation-Particle Regulatory Instrumentation Demonstration Experiment (A-PRIDE) [24,25] programmes.

While the new regulatory standard specifies systematic measurement of aircraft engine nvPM emissions at the instrument location, the sampling system requirements coupled with the small particle mean diameters observed from aircraft engines [5-8] result in a significant sizedependent particle losses of up to $90 \%$ for nvPM number and $50 \%$ for nvPM mass $[15,26]$, prior to the measurement by the calibrated instruments. The nvPM mass and number concentrations at the Engine Exit Plane (EEP) can be estimated by accounting for these physical losses in the sampling and measurement system.

Aircraft engine nvPM emissions are influenced by the underlying physical properties and chemical composition of the fuel being burned, especially the fuel aromatic content, which varies globally by several percent for conventional jet fuel $[27,28]$. Sustainable aviation fuels are increasingly being sought as replacements for conventional fossil fuels, which have additional benefits in terms of lower emissions [29-32], reduced contrail formation [33], and improved local air quality in the vicinity of airports [34]. The blending of conventional jet fuels with synthetic paraffinic fuels have been shown to reduce aircraft engine nvPM emissions, that scale inversely with higher fuel hydrogen content and lower fuel aromatic content [35]. It has also been shown that for a fuel blend which would meet current ASTM International specifications, a reduction in nvPM number-based emissions of $\sim 35 \%$ and nvPM massbased emissions of $\sim 60 \%$ could be achieved for an aircraft auxiliary power unit (APU) [36].

In 2012, the European Commission funded a collaborative research project - Initiative Towards sustAinable Kerosene for Aviation (ITAKA). The main objectives of the ITAKA project were to (1) develop a full value-chain in Europe to produce sustainable drop-in hydrotreated esters and fatty acids (HEFA) fuels and study the implications of a largescale use, and (2) conduct research on sustainability, economic competitiveness, and technology readiness [37]. The ITAKA project primarily targeted camelina oil as the most promising sustainable feedstock, with used cooking oil (UCO) as an alternative feedstock. Both feedstocks were converted to drop-in aviation fuels through the HEFA pathway.

As part of the ITAKA project framework, the impact of fuel composition on the nvPM emissions of a Garrett Honeywell GTCP85 APU were investigated at three operating conditions burning blends of Jet A-1 and alternative fuels produced from UCO and Camelina feedstocks. The emissions measurements were performed at the University of Sheffield
Low Carbon Combustion Centre during two distinct test campaigns conducted in June 2014 (ITAKA 1) and April 2017 (ITAKA 2). Measurements were independently performed utilising the standardised North American and European reference sampling and measurement systems, respectively, with additional measurements of particle size distributions obtained to facilitate particle loss correction estimates. During ITAKA 1, 16 blends of UCO-HEFA with conventional Jet A-1 were investigated, while 12 blends of Camelina-HEFA and conventional Jet A-1 were used during ITAKA 2. Details of the ITAKA 1 test campaign have been previously reported $[36,38]$. Particle size distribution measurements were used to correct the measured nvPM emissions data for particle losses in the sampling and measurement system, to provide an estimate of the nvPM emissions at the EEP. The impact of fuel composition on nvPM number and mass emissions reductions was subsequently assessed using the EEP data.

\section{Experimental methods}

\subsection{Fuels}

The 18 fuels investigated during the ITAKA 1 campaign were derived from a conventional Jet A- 1 and neat UCO-HEFA, with 16 blends of the two fuels mixed in different proportions. During the ITAKA 2 campaign, 14 fuels derived from a different Jet A-1 and pure Camelina-HEFA fuel were studied with 12 blends of the two fuels mixed at ratios of 10, 20, $30,35,40,50,60,70,80,85,90,95 \%$, by mass. The properties of specific Jet A-1 and alternative fuels (UCO-HEFA and Camelina-HEFA) used during the two ITAKA test campaigns are presented in Table 1. It should be noted that the UCO-HEFA and Camelina-HEFA fuels had a higher net heat of combustion and a higher hydrogen content compared to Jet A-1. The fuel hydrogen content was evaluated using two different methods: ASTM D5291 and two-dimensional gas chromatography (GCxGC) analysis. For the same fuel, differences of $0.05-0.1 \%$ in hydrogen content were reported. In this study, for consistency, only fuel hydrogen content derived from GCxGC data is reported which was used in turn to determine the $\mathrm{H} / \mathrm{C}$ ratio required to calculate nvPM number and mass emission indices, and for subsequent data analysis. The GCxGC analysis was performed using stored volumes of fuels by the same accredited laboratory (Intertek) for all four fuels.

The GCxGC analysis of fuel composition of the Jet A-1, UCO-HEFA, and Camelina-HEFA fuels is presented in Fig. 1. The two Jet A-1 fuels used in the ITAKA 1 and 2 campaigns were different, but each had a distribution of hydrocarbon groups typically found in conventional fuels. The UCO-HEFA and Camelina-HEFA fuels have a higher proportion of iso-Paraffins and lower proportion of cyclo-Paraffins, alkyl benzenes and benzo-cycloparaffins compared to the Jet A-1 fuels.

\subsection{Ambient conditions}

Aircraft engine PM emissions can be affected by ambient conditions. An increase in ambient temperature has been shown to reduce aircraft engine total PM emissions as the warmer ambient air is thought to mitigate volatile aerosol formation [29,39]. However, the influence of ambient environmental conditions on nvPM formation within a gas turbine engine has received little attention and is currently poorly understood [24]. Ambient temperature, ambient pressure, and relative humidity were recorded during the two test campaigns with measured ranges presented in Table 2 . The ambient conditions were significantly different between the ITAKA 1 and ITAKA 2 campaigns, with a median difference of $10.6{ }^{\circ} \mathrm{C}, 38.8 \mathrm{mbar}$, and $19.5 \%$, in temperature, pressure, and relative humidity, respectively.

\subsection{APU operating conditions}

During the ITAKA 1 and ITAKA 2 test campaigns, the same Garrett Honeywell GTC85 APU was used as the source of emissions. It was 
Table 1

Selected properties of the neat fuels used in the ITAKA test campaigns.

\begin{tabular}{|c|c|c|c|c|c|c|}
\hline \multirow{2}{*}{$\begin{array}{l}\text { Test campaign } \\
\text { Property }\end{array}$} & \multicolumn{3}{|l|}{ ITAKA 1} & \multicolumn{3}{|l|}{ ITAKA 2} \\
\hline & Method & Jet A-1 & UCO-HEFA & Method & Jet A-1 & Camelina-HEFA \\
\hline Density at $15^{\circ} \mathrm{C}\left[\mathrm{kg} / \mathrm{m}^{3}\right]$ & IP365 & 805.3 & 759.6 & IP365/D4052 & 806.7 & 779.6 \\
\hline \multicolumn{7}{|l|}{ Distillation temperature $\left[{ }^{\circ} \mathrm{C}\right]$} \\
\hline $10 \%$ boiling point & ASTM D86 & 163.8 & 169.8 & ASTM D86 & 171.0 & 173.2 \\
\hline $90 \%$ boiling point & ASTM D86 & 236.4 & 235.1 & ASTM D86 & 238.3 & 262.8 \\
\hline Final boiling point & ASTM D86 & 259.1 & 251.9 & ASTM D86 & 259.8 & 274.6 \\
\hline Net heat of combustion [MJ $/ \mathrm{kg}]$ & ASTM D3338 & 43.153 & 44.023 & ASTM D3338 & 43.23 & 43.695 \\
\hline Smoke point $[\mathrm{mm}]$ & ASTM D1322 & 23 & $>50$ & ASTM D1322 & 23 & 35.5 \\
\hline Kinematic viscosity at $-20^{\circ} \mathrm{C}\left[\mathrm{mm}^{2} / \mathrm{s}\right]$ & IP71 & 3.521 & 3.885 & D445 & 3.887 & 5.107 \\
\hline Sulphur [mass \%] & ASTM D4294 & 0.033 & $<0.018$ & D4294/D2622 & 0.150 & 0.070 \\
\hline Hydrogen [weight \%] & Calculated from GCxGC & 13.94 & 15.22 & Calculated from GCxGC & 14.00 & 14.80 \\
\hline $\mathrm{H} / \mathrm{C}$ ratio & Calculated from GCxGC & 1.93 & 2.14 & Calculated from GCxGC & 1.94 & 2.07 \\
\hline
\end{tabular}

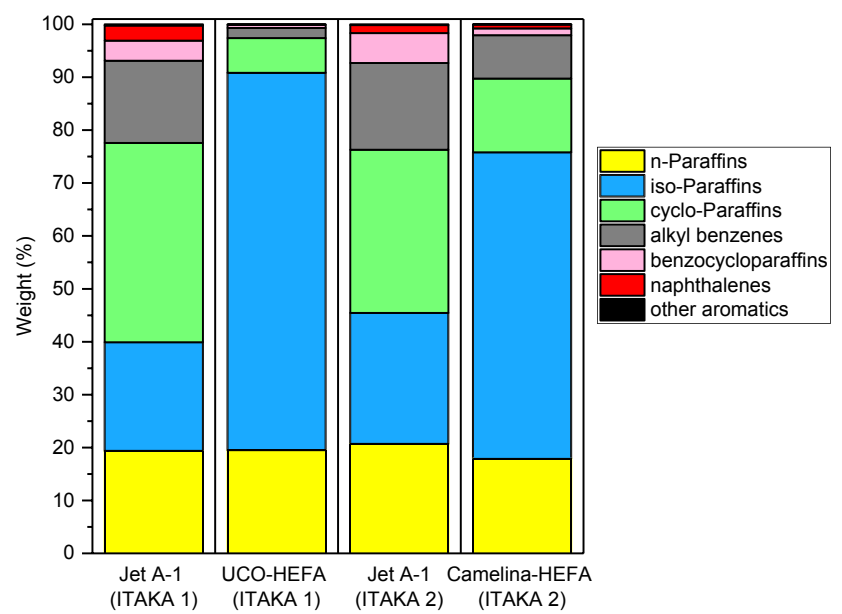

Fig. 1. Chemical composition of conventional and alternative fuels obtained from GCxGC analysis.

Table 2

Ambient conditions recorded during the ITAKA 1 and ITAKA 2 test campaigns.

\begin{tabular}{llll}
\hline & Temperature $\left({ }^{\circ} \mathrm{C}\right)$ & Pressure (mbar) & Relative Humidity (\%) \\
\hline ITAKA 1 & $14.0-20.6$ & $1024.7-1031.1$ & $61-85$ \\
ITAKA 2 & $4.5-6.1$ & $987.2-990.9$ & $86-99$ \\
\hline
\end{tabular}

operated at three conditions: No Load (NL), Environmental Control Systems (ECS), and Main Engine Start (MES). These three conditions correspond to the normal operating conditions for an APU. At each stable APU operating condition, parameters such as fuel flow rate, air-tofuel ratio (AFR), and exhaust gas temperature (EGT) were recorded. The typical APU operational parameters recorded during Jet A-1 runs in both test campaigns are presented in Table 3. The APU operational parameters were highly reproducible and stable during both test campaigns, with the average fuel flow rate, AFR, and EGT all within one standard

Table 3

APU operational parameters at different operating conditions for Jet A-1 runs.

\begin{tabular}{cllllll}
\hline $\begin{array}{l}\text { Test } \\
\text { campaign }\end{array}$ & $\begin{array}{l}\text { ITAKA } \\
1\end{array}$ & $\begin{array}{l}\text { ITAKA } \\
2\end{array}$ & $\begin{array}{l}\text { ITAKA } \\
1\end{array}$ & $\begin{array}{l}\text { ITAKA } \\
2\end{array}$ & $\begin{array}{l}\text { ITAKA } \\
1\end{array}$ & $\begin{array}{l}\text { ITAKA } \\
2\end{array}$ \\
\hline $\begin{array}{c}\text { Operating } \\
\text { condition }\end{array}$ & NL & & ECS & & MES & \\
Fuel flow & $17.7 \pm$ & $17.8 \pm$ & $25.8 \pm$ & $25.9 \pm$ & $31.1 \pm$ & $31.8 \pm$ \\
rate (g/s) & 0.2 & 0.2 & 0.3 & 0.2 & 1.1 & 0.4 \\
AFR & 135.0 & 135.9 & $84.4 \pm$ & $84.4 \pm$ & $62.2 \pm$ & $62.2 \pm$ \\
& \pm 3.9 & \pm 3.9 & 0.8 & 0.8 & 1.0 & 1.0 \\
EGT $\left({ }^{\circ} \mathrm{C}\right)$ & 324.1 & $323 \pm$ & 475.2 & 475.8 & 600.0 & 604.3 \\
& \pm 6.0 & 3.7 & \pm 5.0 & \pm 4.6 & \pm 7.6 & \pm 6.2 \\
\hline
\end{tabular}

deviation of the mean.

\section{4. nvPM sampling and measurement systems}

For all tests reported here, the exhaust aerosol produced by the APU was extracted via a single-point stainless probe, $3 / 8$ " in outer diameter (0.0035" wall) positioned within $1 / 2$ nozzle diameter of the APU exit plane $(\sim 100 \mathrm{~mm})$. Downstream of the probe, the North American and European reference sampling and measurement systems were used during the ITAKA 1 and ITAKA 2 campaigns, respectively, to quantify nvPM mass-based emissions, nvPM number-based emissions, and particle size distributions. Both reference systems were operated in compliance with the ICAO standard methodology specified in Appendix 7 of Annex 16 [15], and in SAE ARP 6320 [16]. These reference systems had similar measurement characteristics with minimal differences in employed number and mass analysers, system dimensions, flowrates, and temperatures. The North American mobile reference system was operated by the Missouri University of Science and Technology and has been described previously $[24,25,30]$. The European mobile reference system was operated by Cardiff University with further details described elsewhere $[21,22,25]$. A general description of the experimental set-up employed during both test campaigns is presented here: APU emissions entered the sampling systems via the aforementioned $3 / 8^{\prime \prime}$ stainless steel probe and $7.5 \mathrm{~m}$ long (7.75 $\mathrm{mm}$ inner diameter (ID)) stainlesssteel heated line maintained at $160{ }^{\circ} \mathrm{C}$. The sampled aerosol was then split into three lines, namely a diluted nvPM line, an undiluted line for the measurement of smoke number and gaseous emissions $\left(\mathrm{CO}_{2}, \mathrm{CO}\right.$, and $\mathrm{NO}_{\mathrm{x}}$ ), and a pressure relief line. The nvPM sample was then diluted using an ejector diluter (Dekati DI-1000) using dry nitrogen cooling the nvPM sample to $60^{\circ} \mathrm{C}$ whilst suppressing the potential for particle coagulation, water condensation, and volatile particle formation in the sample lines. The dilution factor was derived from raw (gas line) and diluted (nvPM line) $\mathrm{CO}_{2}$ concentrations, which were measured using a suitably ranged NDIR $\mathrm{CO}_{2}$ analyser as specified by ARP 6320 [16]. A $25 \mathrm{~m}$ long antistatic polytetrafluoroethylene (PTFE) sample line maintained at $60{ }^{\circ} \mathrm{C}$ transported the diluted aerosol to the nvPM analysers. A $1 \mu \mathrm{m}$ sharp-cut cyclone was placed prior to the measurement analysers for protection and to limit line shedding interference. The nvPM number concentration was measured using an AVL Particle Counter (APC) Advanced consisting of a n-butanol based TSI 3790E Condensation Particle Counter (CPC) and a volatile particle remover (VPR) consisting of a catalytic stripper in between a two-stage rotary diluter and a porous tube diluter to remove volatile particles and further dilute the sample. The nvPM mass concentration was measured using an AVL Micro Soot Sensor (MSS) and an Artium Laser Induced Incandescence LII 300, however, to enable comparison, only data from the MSS is reported here.

During both test campaigns, in compliance with ICAO Annex 16 [15], the dilution factor was maintained in the range 8-14, averaging $11.7 \pm 1.3$ during ITAKA 1 and $10.7 \pm 0.8$ during ITAKA 2 . Performance evaluation and comparison of the North American and European 
standardised reference systems for the measurement of aircraft engine nvPM number and mass emissions has been previously established using a CFM56-7B26/3 engine [22,25].

Additional particle size distribution (PSD) measurements, currently not prescribed by the ICAO standard methodology, were performed using calibrated DMS 500 fast-mobility spectrometers (Cambustion Ltd). The DMS 500 provides a measure of the particle size distribution in terms of electrical mobility, and has been frequently used to report size distribution characteristics of aircraft engine PM emissions [36,40,41]. In this analysis, it was ensured that consistent DMS 500 inversion matrices were selected to allow comparative size distribution data between the two test campaigns.

\subsection{Test matrix and measurement methodology}

The APU was initially put through a warmup sequence prior to operation with different fuels. For each fuel tested, one test cycle corresponded to a stair-wise step down from MES to ECS to NL, which was repeated once without APU shutdown. This procedure minimised differences in the APU temperature and, hence, potential differences in the fuel vaporization rate that may contribute to measurement uncertainties. Blends of Jet A-1 and alternative fuels were randomly selected (non-sequential) to mitigate potential bias and drift. The nvPM emissions using neat Jet A-1 were recorded daily and used as a baseline to monitor the APU performance and measurement system repeatability during each campaign. Cleanliness and background checks for the nvPM number and mass analysers were also performed daily in conformity with standard methodology [15].

Each nvPM data point corresponds to an average of at least two (up to six for Jet A-1) repeats recorded over stable periods of 30 seconds to 2 minutes. At stable APU operating conditions, the averaged Coefficient of Variation (CV) over both test campaigns was $1.1 \pm 0.4 \%$ for nvPM number concentration and $3.3 \pm 1.5 \%$ for nvPM mass concentration.

\section{6. nvPM data analysis (Emission indices and particle loss correction)}

The nvPM number and mass emissions are reported as Emission Indices (EIs) at the measurement location and at the EEP. The EI metric was used to assess the engine emissions for different operating conditions per unit mass of fuel burned $[15,16]$, with the simplified equations for the EIs at the measurement location given below:

$\mathrm{EI}_{\text {number-meas }}\left[\# / k g_{\text {fuel }}\right]=\frac{\mathrm{nvPM}_{\text {num-STP }} \times \mathrm{DF}_{2} \times 22.4 \times 10^{6}}{C O_{2 \text { dil }} \times\left(M_{\mathrm{C}}+\alpha \times M_{\mathrm{H}}\right)}$

$\mathrm{EI}_{\text {mass-meas }}\left[g / k g_{\text {fuel }}\right]=\frac{\mathrm{nvPM}_{\text {mass-STP }} \times 22.4 \times 10^{-6}}{C O_{2 \text { dil }} \times\left(M_{\mathrm{C}}+\alpha \times M_{\mathrm{H}}\right)}$

with " $\mathrm{nvPM}_{\text {num-STP }} \mathrm{X} \mathrm{DF}_{2}$ " the secondary stage dilution (in the VPR) corrected number concentration in particles $/ \mathrm{cm}^{3}$ corrected to Standard Temperature and Pressure (STP: $0{ }^{\circ} \mathrm{C}$ and $101.325 \mathrm{kPa}$ ), nvPM $\mathrm{n}_{\text {mass-STP }}$ the measured mass concentration in $\mu \mathrm{g} / \mathrm{m}^{3}$ corrected to STP, $\mathrm{CO}_{2 \text { dil }}$ the diluted $\mathrm{CO}_{2}$ concentration at the number and mass analysers in molar fraction, $M_{\mathrm{C}}$ and $M_{\mathrm{H}}$ the molar masses of carbon and hydrogen, respectively, and $\alpha$ the hydrogen to carbon (H/C) ratio of the fuel.

The EEP nvPM number and mass EIs were calculated from measured EIs by correcting for particle loss using Eq. (3).

$\mathrm{EI}_{\mathrm{EEP}}=\mathrm{EI}_{\text {meas }} \times k_{\mathrm{SL}} \times k_{\mathrm{thermo}}$

where $\mathrm{EI}_{\text {meas }}$ is the measured nvPM number/mass EI calculated using Eqs. (1) and (2), $k_{\text {thermo }}$ is the thermophoretic particle loss correction factor for the extraction section of the sampling system $[15,16]$, and $k_{\mathrm{SL}}$ is the system particle loss correction factor (excluding thermophoretic loss in the extraction section) as discussed below. It should be noted that given the scope of this paper was to compare the nvPM emissions reported by the two reference systems, the energy content of the fuel was not considered. However, fuel energy content correction should be included when assessing the impact of fuel composition on local air quality, since for the same operating condition different mass flow rate of fuel would need to be burned. For the fuels investigated in this study, the HEFA fuels had a higher energy content which would have corresponded to a small reduction in emitted nvPM $(\leq 2 \%)$.

Historically, loss correction factors have been experimentally determined by measuring particle size distributions upstream and downstream of a sampling system $[8,39,42,43]$. When particle size distribution measurements at both ends of the sampling system are not possible, a particle loss correction factor can be estimated using the United Technologies Research Center (UTRC) particle transport model predicting size-dependent particle loss based on sampling system configuration data, as described in SAE AIR 6504 [44]. The UTRC model can be combined together with the measured particle effective density and the measured particle size distribution to estimate EEP number and mass emissions $[7,40,45]$. In this analysis, the system loss correction factors $\left(k_{\mathrm{SL}}\right)$ for nvPM number and mass were determined using the measured particle size distributions and the UTRC model as follows: For each sampling system, the number, mass, and size loss functions ( $f_{\text {loss }}$ ) were determined by combining the particle losses in the system determined using the UTRC model with VPR, CPC, and cyclone penetration functions derived from calibration data and manufacturer specifications, as discussed in Appendix 8 of ICAO Annex 16 [15]. In this context, the loss functions $f_{\text {loss }}$ represents size-dependent losses of the sampled particles between the sampling system inlet (i.e. EEP) and the analysers (i.e. measurement location). Particle size distributions were estimated at the EEP by dividing the measured size distributions by the predicted loss function $\left(\mathrm{PSD}_{\mathrm{EEP}}=\mathrm{PSD}_{\text {measured }} / f_{\text {loss }}\right)$. System loss correction factors $\left(k_{\mathrm{SL}}\right)$ were obtained by dividing the nvPM number/mass concentration derived from the particle size distribution at the nvPM number/mass analyser location with the nvPM number/mass concentration derived from the particle size distribution at the EEP. For the calculation of the nvPM mass correction factors, nvPM number-based size distributions were converted into mass-based size distributions using Eq. (4), and assuming particle sphericity and an effective density of $1 \mathrm{~g} / \mathrm{cm}^{3}$ as typically assumed for aircraft engine nvPM $[26,40]$.

$$
\begin{aligned}
\operatorname{Mass}\left(d_{\mathrm{p}}\right) & =\operatorname{Number}\left(d_{\mathrm{p}}\right) \times \operatorname{Volume}\left(d_{\mathrm{p}}\right) \times \rho_{\text {eff }}\left(d_{\mathrm{p}}\right) \\
& =\frac{\operatorname{Number}\left(d_{\mathrm{p}}\right) \times \pi \times \rho_{\text {eff }}\left(d_{\mathrm{p}}\right) \times d_{\mathrm{p}}^{3}}{6}
\end{aligned}
$$

Other characteristic parameters were derived from the EEPestimated particle size distributions, such as the number-based geometric mean diameter (GMD) and geometric standard deviation (GSD) to compare the data from the two campaigns in terms of particle sizerelated parameters.

\section{Results and discussion}

\subsection{Measured nvPM emissions}

\subsubsection{Measured nvPM number and mass}

The nvPM number and mass EIs measured during the two ITAKA test campaigns across the range of fuel blends and APU operating conditions are presented in Fig. 2. The fuel hydrogen content was selected as the parameter to compare the data from the two campaigns, as it has been shown to better correlate with sooting propensity than the fuel aromatic content $[32,35,45]$.

The nvPM number and mass EIs at the measurement location for both test campaigns were observed to decrease with increasing fuel hydrogen content regardless of the fuel composition or APU operating condition, in agreement with the literature $[32,36,45]$. When comparing campaign specific nvPM emissions at the different APU operating conditions (Fig. 2 (a)-(c)-(e) and (b)-(d)-(f)), the nvPM number and mass EIs decrease with increasing APU fuel flow rate (corresponding to the 

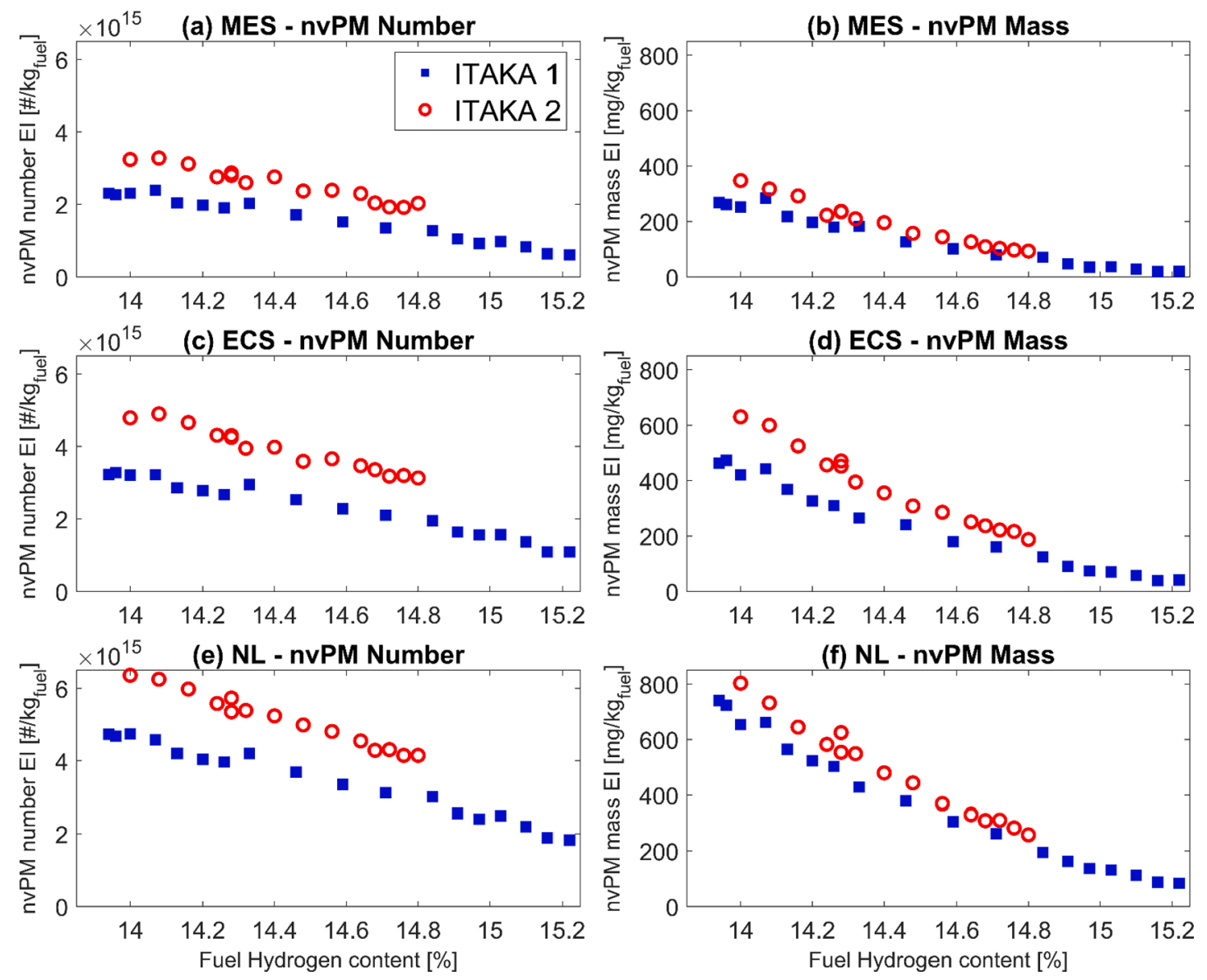

Fig. 2. Measured nvPM number- (a)(c)(e) and nvPM mass- (b)(d)(f) -based EIs as a function of fuel hydrogen content for the three APU operating conditions.

different operating conditions (Table 3)), suggesting that the APU combustion efficiency increases from NL to ECS to MES as has been previously observed [36].

For a given fuel hydrogen content, the nvPM EIs at the measurement location reported for the ITAKA 2 campaign are consistently higher, on average $28 \%$ for nvPM number and $15 \%$ for nvPM mass across the three APU operating conditions. As discussed in previous work [25], the levels of uncertainty in nvPM EI mass and number measurements were $22 \%$ and $25 \%$ respectively, with empirically derived data during parallel measurement of three ICAO compliant sampling and measurement systems on a CFM56-7B26/3 engine. In addition to the nvPM measurement uncertainty, the observed differences between the ITAKA 1 and ITAKA 2 datasets can be further explained by: the different ambient conditions (Table 2) with the lower ambient temperature recorded during ITAKA 2 inducing lower quenching temperature and hence higher soot production, engine wear between the two test campaigns, different fuel compositions (Table 1 and Fig. 1), and spatial inhomogeneity of the exhaust stream (i.e. different sampling location of the probe in the exhaust stream).

It should be noted that the repeatability associated with nvPM measurement specific to each test campaign was quantified by repeating daily measurements using the conventional Jet A-1 (up to 6 repeats per test campaigns), with a standard deviation of $\leq 5.1 \%$ for measured nvPM number EI and $\leq 4.7 \%$ for measured nvPM mass EI.

\subsubsection{Measured particle size distributions}

The typical EI-weighted particle size distributions measured with a DMS 500 during ITAKA 1 and ITAKA 2 for selected fuels at the three APU operating conditions are presented in Fig. 3, from which the statistical GMD and GSD were calculated at the measurement location. The GMD varied from 22.6 to $43.0 \mathrm{~nm}$ with a GSD of 1.59 - 1.78 for the ITAKA 1 dataset, and for ITAKA 2, the GMD ranged from 30.1 to $44.9 \mathrm{~nm}$ with a GSD of 1.77 - 1.9. The nvPM number concentration (obtained from integrating the area under the particle size distribution) and GMD were observed to decrease with increasing proportion of alternative fuel (i.e. higher fuel hydrogen content) and increasing fuel flow rate (Table 3).

The particle size distributions at the measurement location generally appeared monomodal and near lognormal, with a good correlation between the two test campaigns. However, for some conditions a small shoulder was observed at $\approx 20 \mathrm{~nm}$, thought to be an artifact of the DMS 500 inversion matrix for the calibration file used.

\subsection{Engine exit plane $n v P M$ emissions}

Currently, the nvPM number and mass EIs at the measurement location (corrected for size-independent thermophoretic loss in the aerosol extraction section of the sampling system) are used for aircraft engine emissions certification [15]. Size-dependent particle losses are not factored into the EIs reported for emissions certification. This would therefore lead to an underestimation of EEP EIs and bias the impact of fuel composition on nvPM emissions produced by the engine. Particleloss-corrected EEP concentrations, as would be required for airport emissions inventories and environmental impact assessment, are therefore essential to better interpret the overall impact of fuel composition on nvPM number and mass emissions reduction.

\subsubsection{Particle loss correction factors}

The nvPM number and mass loss correction factors used to predict the EEP nvPM emissions, and calculated as described in section $\mathbf{2 . 6}$ are presented in Table 4 . As expected, $k_{S L_{\text {number }}}$ is observed to be larger than 

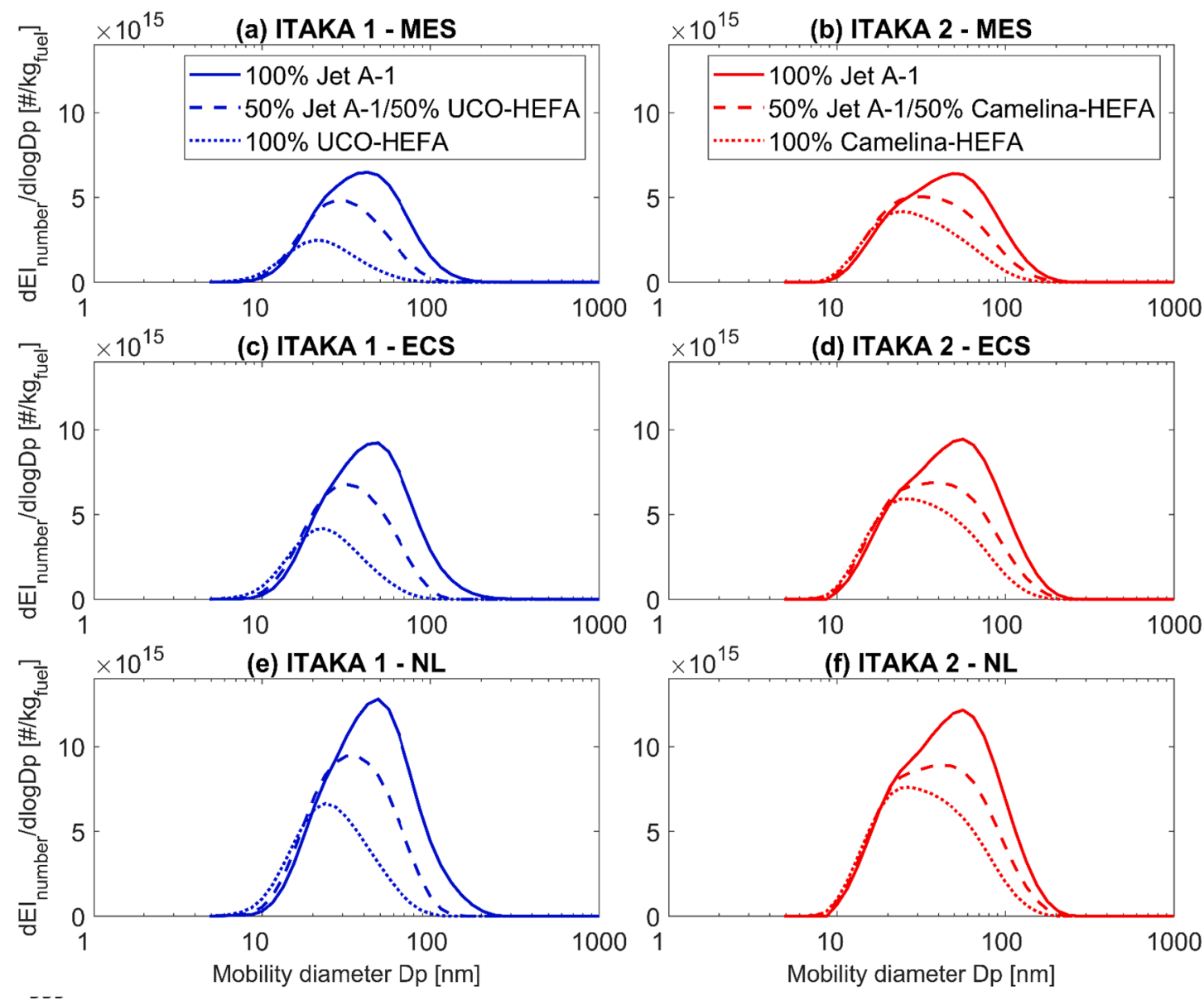

Fig. 3. "EI number"-weighted particle size distributions at the measurement location for different fuel blends and for the three APU operating conditions.

Table 4

System loss correction factors for the two test campaigns.

\begin{tabular}{lll}
\hline Test campaign & $\boldsymbol{k}_{S L_{\text {number }}}$ & $\boldsymbol{k}_{S L_{\text {mass }}}$ \\
\hline ITAKA 1 & $2.21-4.70$ & $1.13-1.40$ \\
ITAKA 2 & $2.32-3.40$ & $1.12-1.20$ \\
\hline
\end{tabular}

$k_{S L_{\text {mass }}}$ given the higher diffusion losses reported at smaller sizes. A broader range of correction factors were calculated for the ITAKA 1 dataset as a consequence of the smaller GMDs and GSDs as well as broader range of fuel blends investigated relative to the ITAKA 2 campaign (Fig. 3). It should be noted that the system loss corrections factors were generally higher at the highest APU operating condition (MES) because of the generally smaller mean particle diameter observed at this condition.

\subsection{2. nvPM number and mass emissions}

The particle-loss-corrected EEP nvPM number and mass EIs for the two campaigns are presented in Fig. 4. As expected and in agreement with the measured nvPM EIs (Fig. 2), EEP nvPM number and mass EIs were observed to reduce with increasing fuel hydrogen content. However, EEP nvPM EIs were higher than the corresponding nvPM EIs at the measurement location, on average $70 \%$ for number $(\leq 84 \%)$ and $30 \%$ for mass $(\leq 45 \%)$, consistent with the standard methodology [44].

Similar to what was observed with measured nvPM emissions (section 3.1.1), the calculated EEP nvPM EIs remain consistently larger during ITAKA 2 for a given fuel hydrogen content when compared to ITAKA 1, with particle loss correction not having a significant effect on this trend.

\subsubsection{GMD and GSD}

The particle size distribution parameters, GMD and GSD, were computed from the EEP-corrected particle size distributions and evaluated as a function of fuel hydrogen content. A decrease in GMD was observed with increasing fuel hydrogen content at the three APU operating conditions for both test campaigns (Fig. 5), with EEP GMDs varying $16.6-36.5 \mathrm{~nm}$ for ITAKA 1 and $23.0-35.4 \mathrm{~nm}$ for ITAKA 2 . The reduction in EEP GMD with increasing fuel hydrogen content was consistent between the two test campaigns (Fig. 5), highlighting that fuel hydrogen content is also a strong correlating parameter for mean particle size reduction. The correlation between GSD and fuel hydrogen content was less apparent with a small reduction observed for ITAKA 2 (GSD: 1.79 - 2.02) and no correlation observed for ITAKA 1 (GSD: 1.68 1.88).

\subsection{Normalised engine exit plane $n v P M$ emissions}

As seen in Fig. 1 and Table 1, the Jet A-1 and alternative fuels evaluated in the ITAKA 1 and ITAKA 2 campaigns had different chemical compositions. As such, in order to isolate the specific impact of fuel composition on nvPM emissions reduction observed during the two campaigns, whilst minimising uncertainties associated with engine wear, measurement uncertainty, ambient conditions, and sampling representativeness, the EEP nvPM data was normalised to a common fuel hydrogen content measured for both ITAKA test campaigns (i.e. $14.33 \%$ ). The data was presented as a percent difference in EEP nvPM EI relative to Jet A-1 fuel with $\mathrm{H}_{\text {content }}=14.33 \%$, as defined in Eq. (5). 

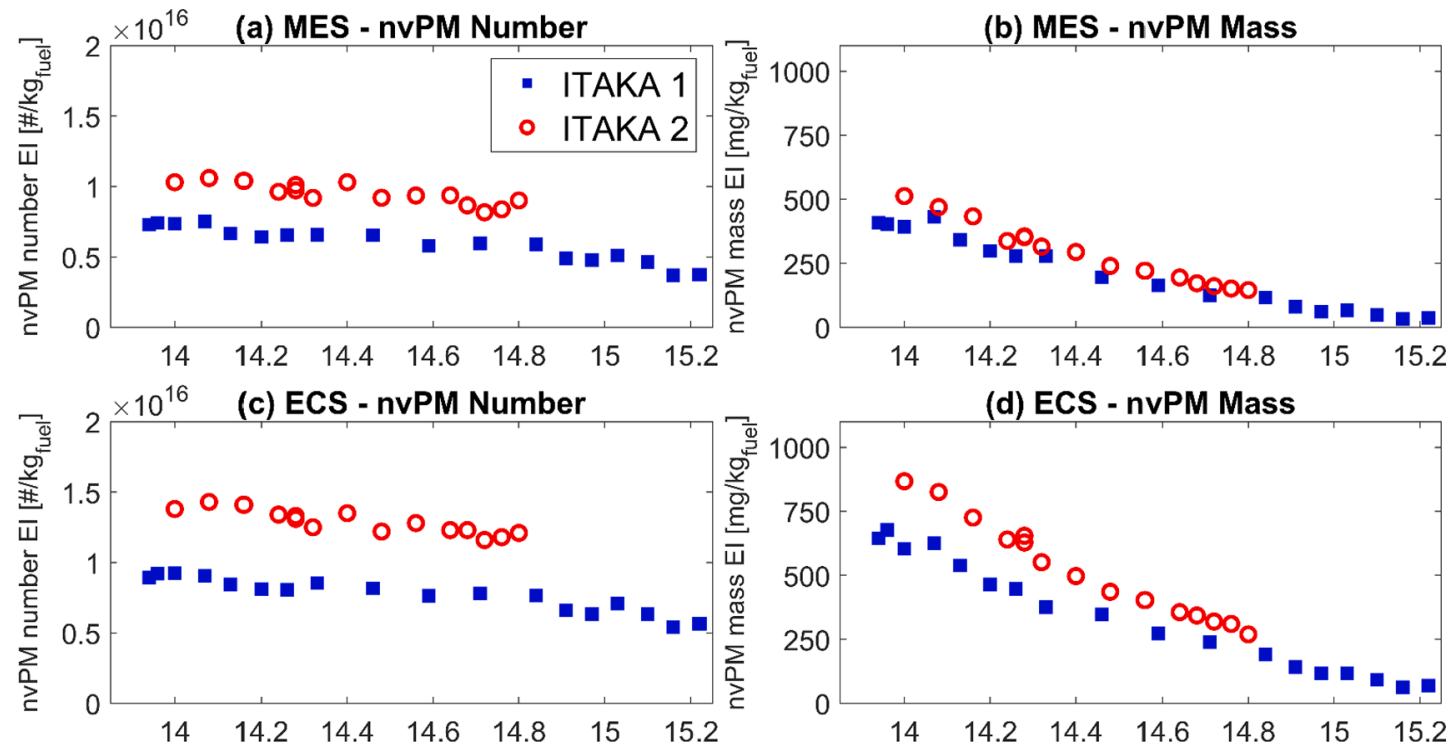

(d) ECS - nvPM Mass
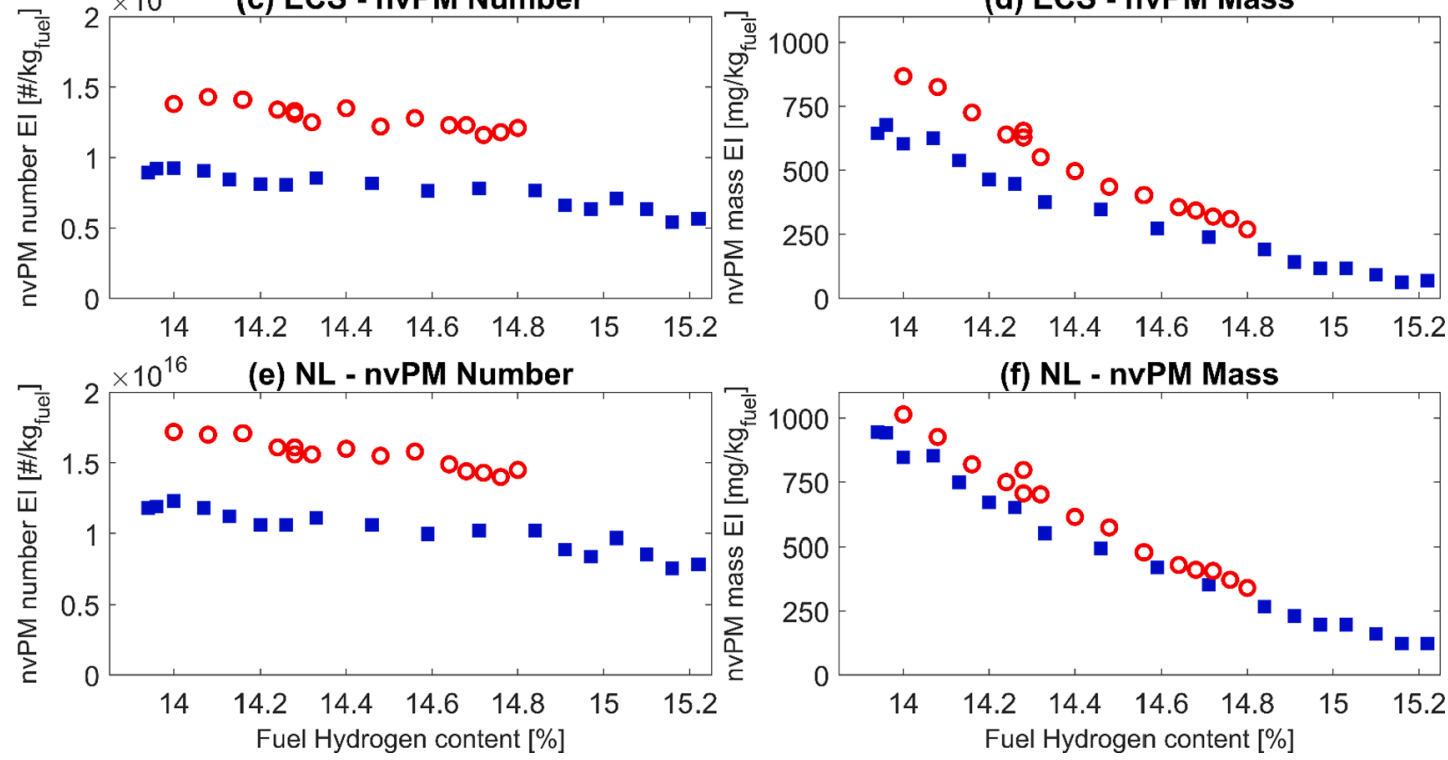

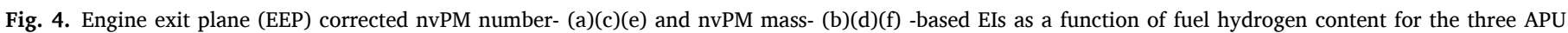
operating conditions.

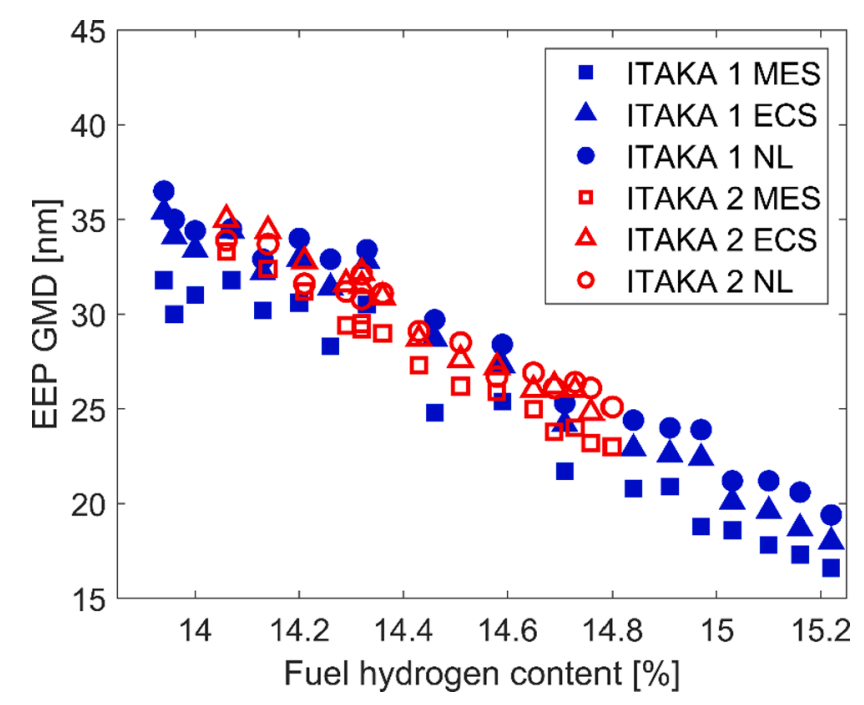

Fig. 5. Geometric Mean Diameter from the EEP-corrected particle size distributions as a function of fuel hydrogen content.

Percent difference (relative to $\mathrm{H}_{\text {content }=14.33 \%}$ )

$$
=1-\frac{\text { EEPnvPMEI }_{\mathrm{H}_{\text {content }}=\mathrm{X} \%}}{\operatorname{EEPnvPMEI}_{\left(\mathrm{H}_{\text {content }}=14.33 \%\right)}}
$$

It should be noted that the data was normalised to a nominally similar fuel hydrogen content reported for both campaigns and not to the conventional Jet A-1 as was previously performed for ITAKA 1 [36].
This approach accounts for the fact that the expected nvPM emissions vs. fuel hydrogen content correlations are non-linear, and that the Jet A-1 fuels used in ITAKA 1 and 2 had different fuel hydrogen contents (Table 1).

\subsection{1. nvPM number and mass reductions}

Percentage reductions of EEP-corrected nvPM EIs (normalised to the $14.33 \%$ fuel hydrogen content datum) as a function of fuel hydrogen content are presented in Fig. 6 for the two campaigns. Similar to the EIs at the measurement location and EEP, the normalised EEP nvPM EIs were observed to decrease with increasing fuel hydrogen content for both ITAKA campaigns. The EEP nvPM mass EI percentage reduction with increasing fuel hydrogen content were significantly higher than that of the EEP nvPM number EI, which can be explained by the fact that the particle size distribution shifted to smaller sizes (Fig. 5), which affects nvPM mass emissions more than nvPM number emissions. These results indicate that the fuel hydrogen content is a suitable correlating parameter for nvPM reduction adequately capturing differences in fuel composition for the two HEFA fuels and blends used in the ITAKA 1 and 2 campaigns.

Since the trend and magnitude of EEP nvPM percentage reductions for each of the three APU operating conditions during both campaigns were similar, the overall percent difference in nvPM emissions for the GTCP85 APU was further assessed by combining the data from the two campaigns (Fig. 7). The EEP nvPM EI percentage differences for both test campaigns at all three APU operating conditions were observed to be in good statistical agreement, as evidenced by the high coefficient of determination values for the second order polynomial fit to the data $\left(\mathrm{R}^{2}\right.$ $=0.84$ for nvPM number and $\mathrm{R}^{2}=0.97$ nvPM mass), and by the relatively low average difference between the fit and the measured data (3.6 

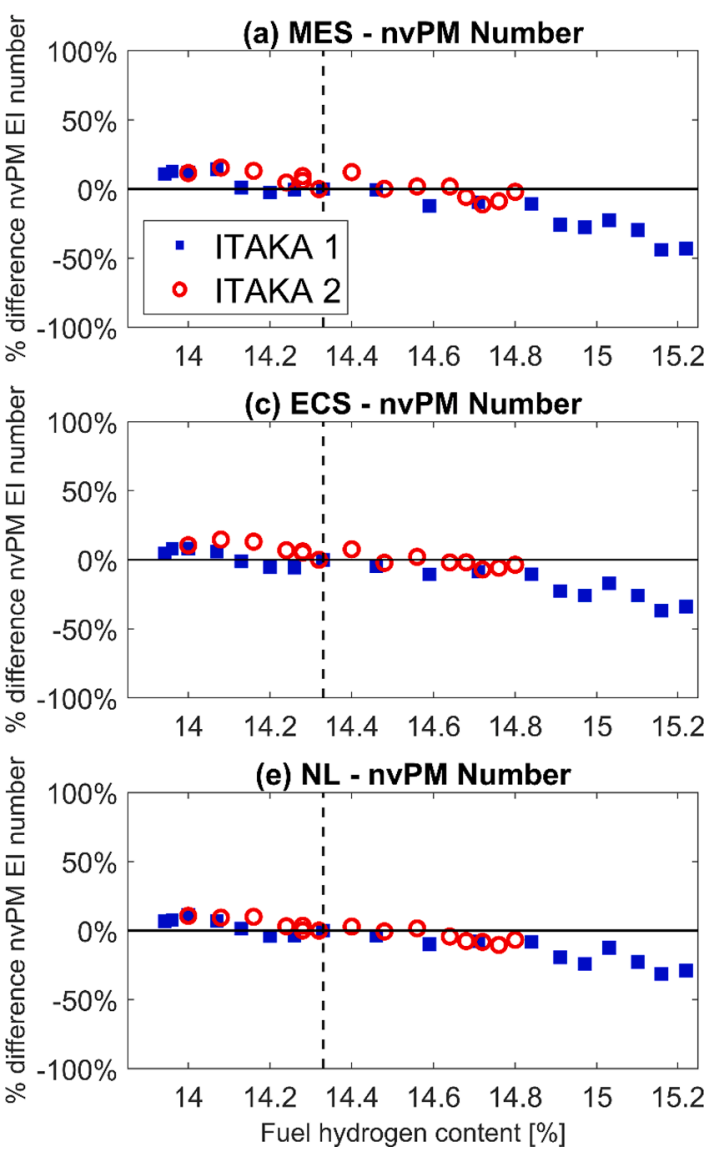

(b) MES - nvPM Mass

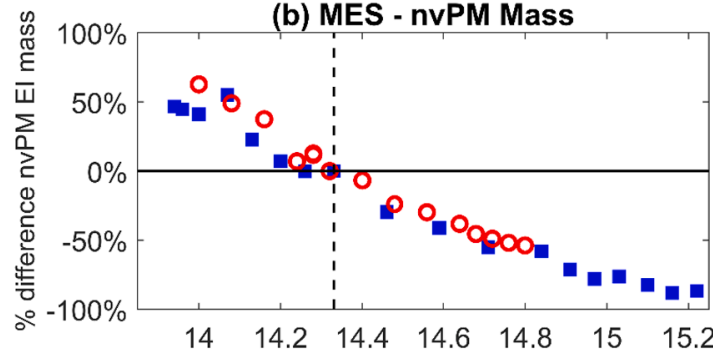

(d) ECS - nvPM Mass
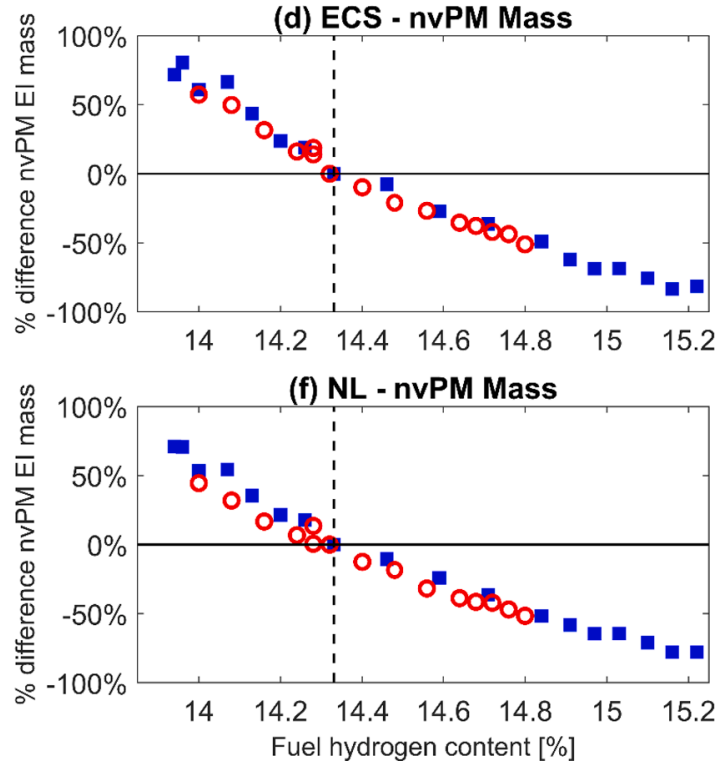

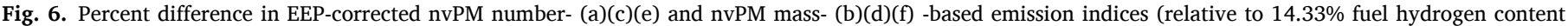
data) as a function of fuel hydrogen content for the three APU operating conditions.

$\pm 2.8 \%$ for nvPM number and $5.8 \pm 4.6 \%$ for nvPM mass). It should be noted that the percentage difference equations given in Fig. 7 are only valid for the investigated APU and operating conditions with the selected fuels and may not be applicable to other engines or fuels. However, this analysis method can be applied to emissions data from other engine types to compare the reduction in nvPM emissions for sustainable aviation fuels and blends.

\section{Conclusion}

The nvPM number and mass emissions and particle size distributions from a GTCP85 aircraft APU burning blends of two alternative fuels
(UCO-HEFA and Camelina-HEFA) blended with different batches of conventional Jet A-1 fuel were measured at different operating conditions during two separate test campaigns, ITAKA 1 and ITAKA 2. The North American mobile reference system was used during ITAKA 1 and the European mobile reference system was used during ITAKA 2.

The results of this work have confirmed that the fuel hydrogen content is a well-suited parameter to correlate EEP nvPM emissions reductions, within the current measurement uncertainty, using standardised sampling and measurement reference systems. Increasing the fuel hydrogen content was shown to significantly reduce nvPM EIs at the measurement location and at EEP. The absolute nvPM number and mass emissions were consistently higher during ITAKA 2 which can be
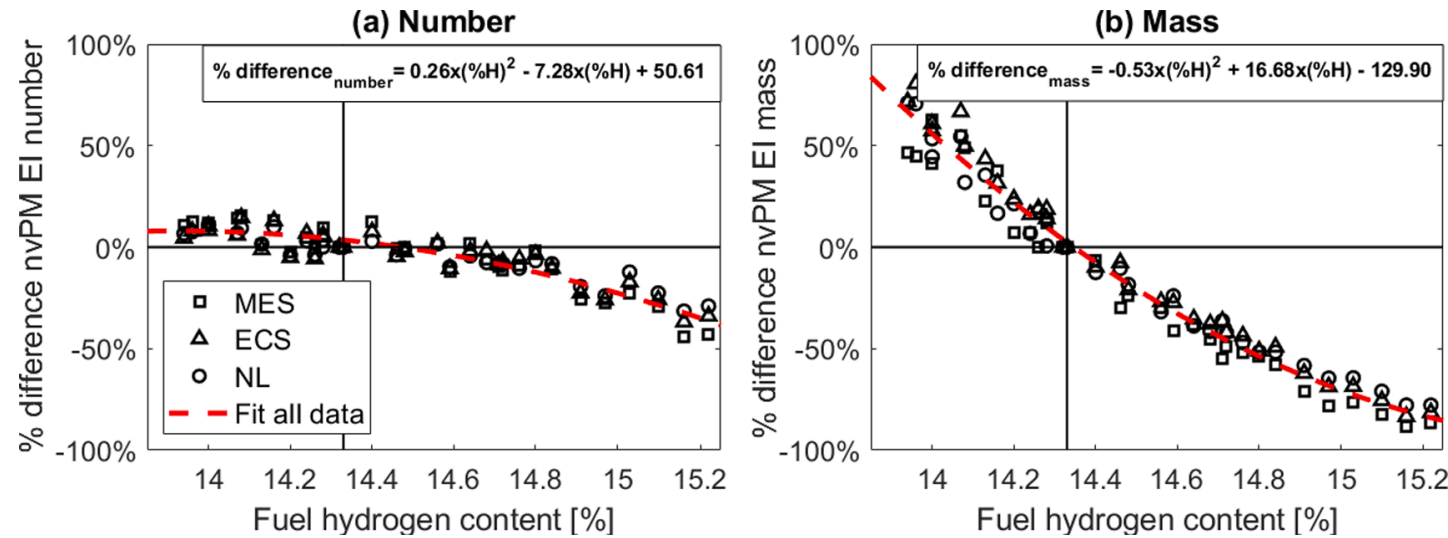

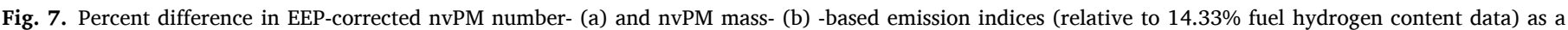
function of fuel hydrogen content (i.e. $\% \mathrm{H}_{\text {content }}$ ) combining data for the three APU operating conditions from the two ITAKA test campaigns. 
attributed to a number of factors including emission source variability (ambient conditions, exhaust stream spatial inhomogeneity, engine wear, etc) and measurement uncertainty (calibration tolerances, dilution factor measurement, etc) between the two ITAKA test campaigns. Given the two investigated alternative fuels have relatively similar fuel compositions and the common APU source, the findings of this study should be further validated using fuels of significantly different chemical composition and physical properties in different engine types to validate the overall reduction in nvPM emissions and the potential improvement to local air quality that the adoption of sustainable aviation fuels may offer.

The results of this work also highlight that particle loss correction is critical to accurately quantifying EEP nvPM emissions and reduction, which can be used to assess the impact on local air quality. A standard procedure to correct for particle loss in a standard sampling and measurement system using nvPM number and mass emissions data is currently available $[26,44]$, however it assumes a GMD and GSD, and it does not include a measurement of particle size distribution to assess losses as presented in this work. Further work would also be required to quantify the impact of ambient condition, engine variability, sampling representativeness, and system-to-system measurement variability on nvPM measurement to better explain the systematic differences in the measured nvPM emissions between ITAKA 1 and ITAKA 2 which would enable better quantification of the impact of fuel hydrogen content.

\section{CRediT authorship contribution statement}

Eliot Durand: Conceptualization, Methodology, Software, Validation, Investigation, Resources, Data curation, Writing - original draft, Writing - review \& editing, Visualization. Prem Lobo: Conceptualization, Methodology, Validation, Investigation, Resources, Data curation, Writing - review \& editing, Visualization, Supervision, Project administration, Funding acquisition. Andrew Crayford: Conceptualization, Methodology, Writing - review \& editing, Supervision, Project administration, Funding acquisition. Yura Sevcenco: Methodology, Investigation, Resources. Simon Christie: Conceptualization, Methodology, Resources, Writing - review \& editing, Supervision, Project administration, Funding acquisition.

\section{Declaration of Competing Interest}

The authors declare that they have no known competing financial interests or personal relationships that could have appeared to influence the work reported in this paper.

\section{Acknowledgments}

This work was partly supported by the European Union's Seventh Framework Programme under Grant Agreement 308807 ITAKA (Initiative Towards sustAinable Kerosene for Aviation), an EASA framework contract concerned with Support on technical issues associated with aviation emissions (EASA.2015.FC21), with support for the preparation of this paper funded by the EU Horizon 2020 AVIATOR project (Grant agreement ID: 814801), and the FLEXIS project (Welsh European Funding Office Grant 80835). Any opinions, findings, and conclusions or recommendations expressed in this paper are those of the authors and do not necessarily reflect the views of the sponsors.

\section{References}

[1] Advisory Council for Aviation Research and Innovation in Europe (ACARE). Strategic Research \& Innovation Agenda - 2017 Update Volume 1 2017. https: //www.acare4europe.org/sites/acare4europe.org/files/document/ACARE-Strate gic-Research-Innovation-Volume-1.pdf.

[2] ACI. Annual World Airport Traffic Report (WATR) 2018. https://aci.aero/wp-conte nt/uploads/2018/11/WATR_WATF_Infographic_Web.pdf.
[3] Becken S, Shuker J. A framework to help destinations manage carbon risk from aviation emissions. Tourism Management 2019;71:294-304. https://doi.org/ 10.1016/j.tourman.2018.10.023.

[4] Carbon Offsetting and Reduction Scheme for International Aviation (CORSIA) n.d. https://www.icao.int/environmental-protection/CORSIA/Pages/default.aspx (accessed July 2, 2020)

[5] Masiol M, Harrison RM. Aircraft engine exhaust emissions and other airport-related contributions to ambient air pollution: A review. Atmos Environ 2014;95:409-55. https://doi.org/10.1016/j.atmosenv.2014.05.070.

[6] Lobo P, Hagen DE, Whitefield PD, Raper D. PM emissions measurements of inservice commercial aircraft engines during the Delta-Atlanta Hartsfield Study. Atmos Environ 2015;104:237-45. https://doi.org/10.1016/j. atmosenv.2015.01.020.

[7] Boies AM, Stettler MEJ, Swanson JJ, Johnson TJ, Olfert JS, Johnson M, Eggersdorfer ML, Rindlisbacher T, Wang J, Thomson K, Smallwood G, Sevcenco Y, Walters D, Williams PI, Corbin J, Mensah AA, Symonds J, Dastanpour R, Rogak SN. Particle Emission Characteristics of a Gas Turbine with a Double Annular Combustor. Aerosol Sci Technol 2015;49(9):842-55. https://doi.org/10.1080/ 02786826.2015.1078452.

[8] Delhaye D, Ouf F-X, Ferry D, Ortega IK, Penanhoat O, Peillon S, Salm F, Vancassel X, Focsa C, Irimiea C, Harivel N, Perez B, Quinton E, Yon J, Gaffie D. The MERMOSE project: Characterization of particulate matter emissions of a commercial aircraft engine. J Aerosol Sci 2017;105:48-63. https://doi.org/ 10.1016/j.jaerosci.2016.11.018.

[9] Shirmohammadi F, Sowlat MH, Hasheminassab S, Saffari A, Ban-Weiss G, Sioutas C. Emission rates of particle number, mass and black carbon by the Los Angeles International Airport (LAX) and its impact on air quality in Los Angeles. Atmos Environ 2017;151:82-93. https://doi.org/10.1016/j. atmosenv.2016.12.005.

[10] Keuken MP, Moerman M, Zandveld P, Henzing JS, Hoek G. Total and size-resolved particle number and black carbon concentrations in urban areas near Schiphol airport (the Netherlands). Atmos Environ 2015;104:132-42. https://doi.org/ 10.1016/j.atmosenv.2015.01.015.

[11] Jonsdottir HR, Delaval M, Leni Z, Keller A, Brem BT, Siegerist F, Schönenberger D, Durdina L, Elser M, Burtscher H, Liati A, Geiser M. Non-volatile particle emissions from aircraft turbine engines at ground-idle induce oxidative stress in bronchial cells. Commun Biol 2019;2(1). https://doi.org/10.1038/s42003-019-0332-7.

[12] Lee DS, Fahey DW, Forster PM, Newton PJ, Wit RCN, Lim LL, Owen B, Sausen R. Aviation and global climate change in the 21st century. Atmos Environ 2009;43 (22-23):3520-37. https://doi.org/10.1016/j.atmosenv.2009.04.024.

[13] Kärcher B. The importance of contrail ice formation for mitigating the climate impact of aviation: CLIMATE IMPACT OF AVIATION - MITIGATION. J Geophys Res [Atmos] 2016;121(7):3497-505. https://doi.org/10.1002/2015JD024696.

[14] Burkhardt U, Bock L, Bier A. Mitigating the contrail cirrus climate impact by reducing aircraft soot number emissions. npj Clim Atmos Sci 2018;1(1). https:// doi.org/10.1038/s41612-018-0046-4.

[15] Annex ICAO. Environmental Protection Volume 2 -. Aircraft Engine Emissions. 2017;16.

[16] SAE international. ARP 6320 - Procedure for the Continuous Sampling and Measurement of Non-Volatile Particulate Matter Emissions from Aircraft Turbine Engines 2018. https://doi.org/10.4271/ARP6320.

[17] Petzold A, Marsh R. SAMPLE I-Studying, sAmpling and Measuring of Particulate Matter 2009. https://www.easa.europa.eu/document-library/research-reports/ easa2008op13.

[18] Marsh R, Crayford A, Petzold A, Johnson M. SAMPLE II-Studying, sAmpling and Measuring of Particulate Matter II 2011. https://www.easa.europa.eu/documen t-library/research-reports/easa2009op18.

[19] Crayford A, Johnson M. SAMPLE III SC.01- Studying, sAmpling and Measuring of aircraft ParticuLate Emission 2011. https://www.easa.europa.eu/document-libra ry/research-reports/easa2010fc10-sc01.

[20] Crayford A, Johnson M. SAMPLE III SC.02 - Studying, sAmpling and Measuring of aircraft ParticuLate Emission 2012. https://www.easa.europa.eu/document-libra ry/research-reports/easa2010fc10-sc02.

[21] Crayford A, Johnson M. SAMPLE III SC.03- Studying, sAmpling and Measuring of aircraft ParticuLate Emission 2013. https://www.easa.europa.eu/document-libra ry/research-reports/easa2010fc10-sc03.

[22] Crayford A, Johnson M, Sevcenco Y, Williams P. SAMPLE III SC.05 - Studying, sAmpling and Measuring of aircraft ParticuLate Emission 2014. https://www.easa, europa.eu/document-library/research-reports/easa2010fc10-sc05.

[23] Petzold A, Marsh R, Johnson M, Miller M, Sevcenco Y, Delhaye D, Ibrahim A, Williams P, Bauer H, Crayford A, Bachalo WD, Raper D. Evaluation of Methods for Measuring Particulate Matter Emissions from Gas Turbines. Environ Sci Technol 2011;45(8):3562-8. https://doi.org/10.1021/es103969v.

[24] Lobo P, Durdina L, Smallwood GJ, Rindlisbacher T, Siegerist F, Black EA, Yu Z, Mensah AA, Hagen DE, Miake-Lye RC, Thomson KA, Brem BT, Corbin JC, Abegglen M, Sierau B, Whitefield PD, Wang J. Measurement of Aircraft Engine Non-Volatile PM Emissions: Results of the Aviation-Particle Regulatory Instrumentation Demonstration Experiment (A-PRIDE) 4 Campaign. Aerosol Sci Technol 2015;49(7):472-84. https://doi.org/10.1080/02786826.2015.1047012.

[25] Lobo P, Durdina L, Brem BT, Crayford AP, Johnson MP, Smallwood GJ, Siegerist F, Williams PI, Black EA, Llamedo A, Thomson KA, Trueblood MB, Yu Z, Hagen DE, Whitefield PD, Miake-Lye RC, Rindlisbacher T. Comparison of standardized sampling and measurement reference systems for aircraft engine non-volatile particulate matter emissions. J Aerosol Sci 2020;145:105557. https://doi.org/ 10.1016/j.jaerosci.2020.105557. 
Alternative Jet Fuel Blend Ratios. Energy Fuels 2015;29:151016011415009. https://doi.org/10.1021/acs.energyfuels.5b01758.

[26] SAE international. ARP 6481- Procedure for the Calculation of Sampling Line Penetration Functions and Line Loss Correction Factors 2019. https://doi.org/ 10.4271/ARP6481.

[27] Hileman JI, Stratton RW, Donohoo PE. Energy Content and Alternative Jet Fuel Viability. J Propul Power 2010;26(6):1184-96. https://doi.org/10.2514/1.46232.

[28] Petroleum Quality Information System 2013 Annual Report. DEFENSE LOGISTICS AGENCY FORT BELVOIR VA; 2013.

[29] Beyersdorf AJ, Timko MT, Ziemba LD, Bulzan D, Corporan E, Herndon SC, et al. Reductions in aircraft particulate emissions due to the use of Fischer-Tropsch fuels. Atmospheric Chem Phys 2014;14:11-23. https://doi.org/10.5194/acp-14-112014.

[30] Lobo P, Condevaux J, Yu Z, Kuhlmann J, Hagen DE, Miake-Lye RC, Whitefield PD, Raper DW. Demonstration of a Regulatory Method for Aircraft Engine Nonvolatile PM Emissions Measurements with Conventional and Isoparaffinic Kerosene fuels. Energy Fuels 2016;30(9):7770-7. https://doi.org/10.1021/acs. energyfuels.6b01581.

[31] Lobo P, Rye L, Williams PI, Christie S, Uryga-Bugajska I, Wilson CW, Hagen DE, Whitefield PD, Blakey S, Coe H, Raper D, Pourkashanian M. Impact of Alternative Fuels on Emissions Characteristics of a Gas Turbine Engine - Part 1: Gaseous and Particulate Matter Emissions. Environ Sci Technol 2012;46(19):10805-11. https:// doi.org/10.1021/es301898u.

[32] Schripp T, Herrmann F, Oßwald P, Köhler M, Zschocke A, Weigelt D, Mroch M, Werner-Spatz C. Particle emissions of two unblended alternative jet fuels in a full scale jet engine. Fuel 2019;256:115903. https://doi.org/10.1016/j. fuel.2019.115903.

[33] Rojo C, Vancassel X, Mirabel P, Ponche J-L, Garnier F. Impact of alternative jet fuels on aircraft-induced aerosols. Fuel 2015;144:335-41. https://doi.org/ 10.1016/j.fuel.2014.12.021.

[34] Yim SHL, Stettler MEJ, Barrett SRH. Air quality and public health impacts of UK airports. Part II: Impacts and policy assessment. Atmos Environ 2013;67:184-92. https://doi.org/10.1016/j.atmosenv.2012.10.017.

[35] Lobo P, Hagen DE, Whitefield PD. Comparison of PM Emissions from a Commercia Jet Engine Burning Conventional, Biomass, and Fischer-Tropsch Fuels. Environ Sci Technol 2011;45(24):10744-9. https://doi.org/10.1021/es201902e.

[36] Lobo P, Christie S, Khandelwal B, Blakey S, Raper D. Evaluation of Non-Volatile PM Emissions Characteristics of an Aircraft Auxiliary Power Unit with Varying
[37] Chiaramonti D, Prussi M, Buffi M, Tacconi D. Sustainable bio kerosene: Process routes and industrial demonstration activities in aviation biofuels. Appl Energy 2014;136:767-74. https://doi.org/10.1016/j.apenergy.2014.08.065.

[38] Christie S, Lobo P, Lee D, Raper D. Gas Turbine Engine Nonvolatile Particulate Matter Mass Emissions: Correlation with Smoke Number for Conventional and Alternative Fuel Blends. Environ Sci Technol 2017;51(2):988-96. https://doi.org/ 10.1021/acs.est.6b03766.

[39] Lobo P, Hagen DE, Whitefield PD, Alofs DJ. Physical Characterization or Aerosol Emissions from a Commercial Gas Turbine Engine. J Propul Power 2007;23(5): 919-29. https://doi.org/10.2514/1.26772.

[40] Durdina L, Brem BT, Abegglen M, Lobo P, Rindlisbacher T, Thomson KA, Smallwood GJ, Hagen DE, Sierau B, Wang J. Determination of PM mass emissions from an aircraft turbine engine using particle effective density. Atmos Environ 2014;99:500-7. https://doi.org/10.1016/j.atmosenv.2014.10.018.

[41] Hagen DE, Lobo P, Whitefield PD, Trueblood MB, Alofs DJ, Schmid O. Performance Evaluation of a Fast Mobility-Based Particle Spectrometer for Aircraft Exhaust. J Propul Power 2009;25(3):628-34. https://doi.org/10.2514/1.37654.

[42] Durand EF, Crayford AP, Johnson M. Experimental validation of thermophoretic and bend nanoparticle loss for a regulatory prescribed aircraft nvPM sampling system. Aerosol Sci Technol 2020;54(9):1019-33. https://doi.org/10.1080/ 02786826.2020 .1756212$.

[43] Altaher MA, Li H, Williams P, Johnson M, Blakey S. Determination of Particle Penetration Factors in a Particle Transfer Line for Aero Gas Turbine Engine Exhaust Particle Measurement 2014:V04AT04A028. https://doi.org/10.1115/GT201425440.

[44] SAE international. AIR 6504 - Procedure for the Calculation of Sampling System Penetration Functions and System Loss Correction Factors 2017. https://doi.org/ 10.4271/AIR6504.

[45] Brem BT, Durdina L, Siegerist F, Beyerle P, Bruderer K, Rindlisbacher T, RocciDenis S, Andac MG, Zelina J, Penanhoat O, Wang J. Effects of Fuel Aromatic Content on Nonvolatile Particulate Emissions of an In-Production Aircraft Gas Turbine. Environ Sci Technol 2015;49(22):13149-57. https://doi.org/10.1021/ acs.est.5b04167. 